\title{
IDENTITETERNES MØDE, CIVILISATIONERNES SAMMENSTØD?
}

\author{
Martijn van Beek
}

\section{Indledning}

Angrebene på World Trade Center i New York og Pentagon i Washington har udløst en forstærket interesse blandt politikere og det brede publikum for forholdene mellem forskellige kulturelle verdenssyn. Især spørgsmålet om religiøse identiteters betydning har fået fornyet aktualitet i en verden, som i hvert fald siden murens fald i vestlige eliters forståelse har været kendetegnet af en udvikling mod globale markeder, demokrati og internationalt samarbejde. Angrebene mindede verden om, at ikke alle forstår det globale projekt på den samme måde, som George Bush Senior gjorde i 1990, da han udråbte en ny verdensorden. Mens 1990'erne i store dele af den vestlige verden var kendetegnet ved et optimistisk syn på det multikulturelle samfunds muligheder, er trenden nu tilsyneladende vendt i modsat retning. Både i USA og Europa har der siden den 11. september været en hurtig og gennemgribende opbygning af barrikader omkring det kendte, det hjemlige. De andre, især arabere og muslimer generelt, bliver i højere grad fremmed- og fjendtliggjort end tidligere, og i Danmark er det tilsyneladende blevet acceptabelt at betegne en anden religion som en 'ond ideologi', der skal bekæmpes. Disse udviklinger illustrerer, hvordan der i de senere år er lagt større vægt på kulturel identitet som det grundlæggende, det essentielle, i dannelsen af politiske og sociale tilhørsforhold, både på internationalt og nationalt plan.

\section{Kulturfundamentalisme}

Et af de centrale bidrag til debatten om den nye verdensorden har været den amerikanske politolog Samuel Huntingtons tese om civilisationernes sammenstød. Oprindeligt formuleret som et spørgsmål blev problemet i bogform til et postulat: forskelle mellem civilisationer, især mellem hvad han betegner som den vestlige og den islamiske, er uoverkommelige, og forholdet mellem dem er per definition fjendtligt (Huntington 1993, 1996). Huntingtons bog The Clash of Civilisations and the Remaking of World Order fra 1996 er ikke usædvanlig på grund af dens primordialistiske opfattelse af kulturel og religiøs identitet, men fordi den opgiver forestillingen om, at værdier som demokrati, menneskerettigheder og statens sekularisering, som er centrale for vestlig modernitetsforståelse, kan overføres eller spredes til andre civilisationer. ${ }^{1}$ Verena Stolcke (1995) betegner denne måde at tænke verden på som kulturfundamentalisme. Kultur-

\footnotetext{
${ }^{1}$ Denne opgivelse af selve modernitetens projekt, som i flere årtier har præget forholdet mellem Vesten og resten af verden er især bemærkelsesværdigt, fordi Huntington selv var en fortaler for modernisering (Kreutzmann 1998).
} 
fundamentalisme bygger på en ide om, at individer er bærere af en 'pakke' kultur, som de har tilfælles med andre medlemmer af deres kultur. ${ }^{2}$ Selv om disse pakker kan udvise forskelle fra individ til individ, er de ens i forhold til centrale elementer, og dermed kan folk med samme kulturelle baggrund siges at have en fælles identitet. Ethvert individ repræsenterer dermed sin kultur, sin civilisation, sin religion. En dansker inkarnerer danskheden. Denne serialitetens logik (Anderson 1998) underbygges, forstærkes og realiseres gennem sprog og billeder, gennem videnskab og bureaukrati, og er med til at skabe og vedligeholde et menneskesyn og en kulturforståelse, der fortrinsvis, eller i mange tilfælde udelukkende, identificerer individer med deres kulturelle eller religiøse identitet.

Denne måde at forstå kulturel identitet på er langt fra et kulturfundamentalistisk monopol. Også i forskellige former for multikulturalisme forstås identiteter som grundlæggende, totale og eksklusive, men kulturforskellene vurderes som noget positivt. Derimod er kulturfundamentalisme kendetegnet ved en antagelse, at mennesker generelt er xenofober, og at kulturelle forskelle derfor i almindelighed giver anledning til konflikt.

Som Ulf Hannerz (1999) fremhæver, har den antropologiske debat om identitet for længst forkastet denne kulturforståelse. Langt de fleste antropologer forstår kultur processuelt som noget, der skabes, genskabes, forandres og opfindes i praksis. Men kulturbegrebet er blevet en del af den brede offentlige diskurs, og den måde hvorpå man italesætter kultur og identitet i samfundet og i politik, har kun lidt tilfælles med den måde, antropologer og sociologer bruger begrebet på. Det er denne dobbelthed, Martin Sökefeld (2001) inspireret af Clifford Geertz betegner som en dual hermeneutik, der udfordrer teoretiseringen og anvendelsen af centrale begreber som identitet og kultur, især når akademiske diskussioner skal bidrage til at løse konkrete problemer i verden, frem for kun at beskrive den (Marx 1978). Den måde at forstå kulturel identitet på, som Huntingtons tese og udbredelsen af kulturfundamentalisme er udtryk for, skal forstås som et antropologisk og sociologisk spørgsmål, frem for at den forkastes som en misforståelse af, hvordan kulturel identitet egentlig skal forstås. Spørgsmålet om kulturmøder er et udmærket udgangspunkt for en sådan antropologisk analyse af forestillinger om kultur og identitet.

\section{Kulturmøder?}

Selve forestillingen om kulturmøder forudsætter, at der findes kulturer (i flertal), som kan mødes. De herskende kulturopfattelser inden for antropologien har inden for de sidste 3 årtier afvist denne forståelse af kultur, fordi den postulerer klart adskilte, grundlæggende forskellige enheder, som internt er homogene. Afvisningen baseres på forskellige teoretiske udgangspunkter, fra Fredrik Barths transaktionalistiske, processuelle tilgang (1989), til forskellige former for postmoderne anti-essentialisme (f.eks. Bhabha

\footnotetext{
${ }^{2}$ Stolcke fremhæver, at kulturfundamentalisme ikke nødvendigvis indebærer et kulturhierarki, hvorved den adskiller sig fra den klassiske racisme. I praksis vil der ofte være et hierarkisk syn på andre kulturer som mindre udviklede eller ligefrem uciviliserede.
} 
1994; Spivak 1999). På trods af store teoretiske forskelle disse tilgange imellem deler de en kulturopfattelse som en måde at forstå verden på; altså som noget man gør. Kulturmødebegrebet derimod tager udgangspunkt i kulturel identitet som noget man er. Det ontologiserer kulturel identitet (Sökefeld 1999). Identitetsbegrebet fremstår som en kulturalistisk avatar (inkarnation) af biologisk essentialisme (van Beek 2000b).

Selve identitetsbegrebet er med til at skabe dette problem, fordi det ifølge ordbogen refererer til en måde at være på, nemlig at være identisk med sig selv. ${ }^{3}$ Identiteter antages at være kongruente med de sociale relationer, de henviser til, men i realiteten tingsliggøres et begrænset udvalg af disse relationer. Tautologiseringen, som identitetsbegrebet lægger op til, er selvfølgelig ikke tilstrækkelig til at give det den aura af common sense, som Mufti (2000) kalder autenticitetens aura, og som begrebet utvivlsomt har. Naturaliseringen af identitet, det være sig en national, en religiøs eller en etnisk, bliver muliggjort af en hverdagspraksis, der italesætter verden på en måde, der behandler folk som repræsentanter for deres identitetskategorier, og som sætter grænser for de frie, flydende og komplekse identifikationer, som individer ellers går og praktiserer.

Den engelske socialpsykolog Michael Billig (1995) har analyseret, hvordan individer bliver mindet om deres nationale identitet gennem, hvad han kalder en banal nationalisme. Det er ifølge Billig ikke de store nationale begivenheder, der opretholder vores identifikation med nationen, men derimod de små, ubemærkede signaleringer af nationalt tilhørsforhold. Især brugen af lingvistisk deixis, små ord som ‘vi', 'os’, 'dem’ etc., henviser i politikernes retorik, i avisernes og dagligdagens sprog, til det nationale fællesskab, uden at det eksplicit nævnes. På samme måde har antropologen Michael Herzfeld (1992; 1996) påpeget, hvordan stereotypisering er med til at skabe en kulturel intimitet, som klart afgrænser 'dem' fra 'os’. Identiteterne gøres absolutte og eksklusive, med et klart indhold, og dette er en forudsætning for forståelsen af identiteter som noget, der har rødder, noget man skal kende, og som man kan miste (Anderson 1998, 44). Det er denne identitetsforståelse som et entydigt, eksklusivt og nødvendigt (fælles) attribut til individer, som ligger til grund for, hvad Bayart (1997) kalder “l’illusion identitaire”.

Ideen om, at kulturer kan mødes eller støde sammen, tager udgangspunkt i en fetichering af kulturel identitet, hvor identitet ikke bare er tingsliggjort, men tilskrives autonomi og handlekraft (van Beek 2000a). Denne forståelse tenderer mod at behandle identitet som noget, der ligger uden for eller før individernes bevidsthed og handlerum, som et produkt af tidligere socialisering og kognitiv dannelse, og som bliver identisk med selve individet. Hvis denne forståelse kombineres med ideen om kulturernes inkommensurabilitet og principielle antagonisme, er kulturmødet allerede blevet et meget vanskeligt problem. Individer, som mødes inden for rammen af sådanne kulturmøder, forstås ikke som individuelle subjekter, men som repræsentanter for deres kultur eller religion. De er små ‘pakker’ islam eller kristendom, mens deres subjektivitet stort set er

\footnotetext{
3 "Ein Ding ist mit sich selbst identisch. Es gibt kein schöneres Beispiel eines nutzlosen Satzes, der aber doch mit einem Spiel der Vorstellung verbunden ist. Es ist, als legten wir das Ding, in der Vorstellung, in seine eigene Form hinein, und sähen, daß es paßt” (Wittgenstein 1995, 350).
} 
begrænset til at udtrykke typiske kulturelle synspunkter. De er uundgåeligt præget af deres kultur og kan per definition ikke undslippe denne kulturelle baggrund. Repræsentanter for kulturer mødes dermed i høj grad som inkarnerede stereotyper med forventninger til hinanden, som bygger på lignende stereotype forestillinger både om deres egen og den andens kultur. Et møde mellem kulturer på dette grundlag passer til den kulturelle fundamentalisme, som Stolcke og Hannerz beskrev. Men den er hverken tilstrækkelig til at forstå, hvorfor nogle mennesker tænker kulturel identitet på denne måde, eller hvordan denne ide om kulturer og deres inkommensurabilitet forholder sig til individernes sociale og kulturelle praksis.

\section{Ladakhs umulige identitet}

For at belyse ovennævnte problemstillinger vil jeg beskrive forskellige ideer om religiøs og kulturel identitet, sådan som de gennem historien er kommet til udtryk i den nordindiske region Ladakh, og beskrive hvilken betydning, de har haft i den politiske praksis og hverdagens sociale praksis.

Himalayaregionen bliver historisk betragtet som mødested mellem hinduisme og buddhisme, mellem grupper, som taler indoeuropæiske sprog og grupper, som taler tibeto-burmesiske sprog, mellem Syd- og Centralasien, mellem 'mongoloide' og 'indoeuropæiske' racer osv. Ladakhregionen, som ligger i den nordøstlige del af delstaten Jammu og Kashmir på det tibetanske plateau, er ingen undtagelse. I det østlige Ladakh bor næsten udelukkende buddhister, mens befolkningen i det vestlige Ladakh overvejende er shi'a-muslimer. Længere mod vest i Kashmirdalen bor overvejende sunnimuslimer, som taler deres eget kashmiri sprog. På sydsiden af Himalayakæden bor primært hinduer. Geografisk ligger Ladakh indeklemt mellem Indien, Pakistan, ØstTurkestan (Xinjiang) og Tibet; de to sidstnævnte regioner er under kinesisk styre.

Fordi Ladakhs klima, topografi, sprog, arkitektur, og materielle kultur har meget tilfælles med den tibetanske, er området ofte blevet kaldt for 'Vest-Tibet'; selv det shi'itiske Baltistan, som ligger lidt længere nede ad Indus floden i det, der i Indien kaldes "Pakistan Occupied Kashmir", var kendt i vestlig litteratur som det 'lille Tibet'. Men det har også været åbenlyst for enhver betragter, at Ladakhs kultur, sprog, økonomi og folks selvforståelse adskilte sig markant fra central Tibet. At klassificere Ladakh som 'tibetansk' kræver med andre ord en selektiv læsning, og selektiv forglemmelse af områdets specifikke kultur, historie, og befolkning (van Beek 2001).

Muligheden for at klassificere Ladakh som tibetansk medfører bl.a., at man lader muslimerne, som i dag udgør op mod halvdelen af befolkningen, ude af betragtning. Det er nødvendigt, fordi en tibetansk identitet menes at være uløseligt forbundet med buddhismen. En konsekvens af en sådan semantisk renhed, som forestillingen om 'autentisk' tibetansk kultur påkræver, er, at ladakhimuslimer og tibetanske muslimer ikke længere anerkendes som legitime, sande ladakhis eller tibetanere.

Religiøse identifikationer spiller faktisk en vigtig rolle i folks selvforståelse i Ladakh. Det at være nangpa, "nogen som er indenfor”, som buddhister betegner sig selv, betyder noget for folk, mens ladakhimuslimer heller ikke lægger skjul på, at det at være 
muslim har stor betydning for deres selvforståelse. ${ }^{4}$ Pointen er altså ikke, at selve det at identificere folk som forskellige, eller som tilhørende forskellige religioner, er ukendt i regionen. Det er her som overalt blandt mennesker en hverdagspraksis. Men den betydning, disse identiteter tilskrives, forandres radikalt under indflydelse af den eksklusive serialitets logik, der er kendetegnende for identitetsperspektivet.

Mange klassiske etnografiske studier arbejder med et sådant identitetsperspektiv. F.eks. er tidlige studier i Ladakh meget optaget af at identificere de elementer i den lokale kultur, som er buddhistiske: dem der er før-buddhistiske, og dem der er noget tredje. Enkelte elementer, f.eks. munkevæsenet og klosterlivet, blev sammenlignet med en ideel standard, generelt afledt fra enten normative tekster eller fra tibetansk monastisk praksis. Det er indlysende, at konstruktionen af både standarderne og selve de elementer, som skulle sammenlignes, indebar en høj grad af abstraktion, forglemmelse og kreativ fortolkning. De kulturelle idealer, og det er i denne sammenhæng ikke afgørende, om de er lokale eller videnskabelige, findes sjældent eller slet ikke i virkeligheden. Selv hvis der f.eks. fandtes et kloster, som udviste en perfekt monastisk disciplin, så er ethvert kloster tilknyttet en bestemt sekt inden for de mangfoldige religiøse traditioner med hver deres særtræk, som af vestlige religionsvidenskaber under ét blev betegnet som 'den tibetanske buddhisme'. Pointen er ikke at benægte, at der kunne findes fællestræk på bestemte områder, men at vise, at den ekstrapolering fra specifikke ligheder og forskelle til homogeniserede, kulturelle eller endog civilisatoriske enheder er en kreativ proces og ikke bare en kortlægning af det allerede eksisterende. ${ }^{5}$

Sådanne ideer om en ren tibetansk buddhisme, som så skulle være identisk med Ladakhs egentlige kultur, har klare konsekvenser. Hvis en bestemt form for buddhistisk praksis ophøjes til den eneste rigtige, så bliver den mangfoldige, reelt eksisterende religiøse praksis ikke bare heterodoks, men en degenereret form for buddhisme. Og hvis Ladakh er buddhistisk, så er muslimer i Ladakh aldrig nogensinde rigtige ladakhi. Den semantiske renhed, som en eksklusiv identifikation af Ladakh med buddhismen postulerer, bliver dermed et projekt. Etnisk udrensning er baseret på netop denne tankegang.

På den ene side kan man sige, at denne måde at tænke identitet på er for snæver, idet den selektivt reificerer bestemte praksisser til essensen af den autentiske religiøse tradition. Men den ophøjer på den anden side også det religiøse til at være det definitive, det essentielle aspekt ved folks identitet. En ladakhi er buddhist, og muslimer er (kun) muslimer. Denne eksklusive forståelse af identiteter som ensidige og totale, og som ens for alle individer, som tilskriver sig, eller tilskrives denne identitet, er yderst problematisk.

Ligesom religiøs praksis altid allerede er synkretistisk, gælder det også for individer, at de er “synkretistiske subjekter” (Orta 1999), et “synkretistisk selv”, som Carlson har

\footnotetext{
${ }^{4}$ F.eks. accepterer de fleste orthodokse shi'iter i Ladakh ingen mad eller drikke, som er rørt af en ikke shi'it. Disse renhedsregler opfattes af nogle buddhister som fornærmende, fordi de implicerer at buddhister er urene. For buddhister er det netop shi'iterne, som betragtes som urene, fordi de slagter dyr. Buddhister i Ladakh spiser gerne og ofte kød, men praktisk taget alle slagtere er muslimer.

${ }^{5}$ At kortlægning heller ikke er en objektiv, neutral proces er velkendt. Se f.eks. kapitlet om “Census, Map, Museum” i Anderson 1991.
} 
argumenteret for $(2000,117 f)$. Det vil sige, at de er "produktet af en proces af selektiv tilegnelse, hvor individer internaliserer elementer fra stærkt varierende puljer af muligheder.” Selv i den polariserede atmosfære i Sydasien, hvor spændinger mellem religiøse grupper regelmæssigt giver anledning til voldsomme konflikter, er den bevidste erfaring af og identifikation med religion frem for med familie, kaste, eller profession forskellig fra person til person, og disse forskelle kan ikke tilbageføres til en mere fundamental identitet (Kakar 2000).

Lokale selvforståelser i Ladakh reflekterer denne følelse af at stå 'imellem' (inbetweenness). Der findes ikke mange fælles oprindelsesmyter i regionen, men mundtlige overleveringer om bosættelse fremhæver, at folk kom fra forskellige steder. Som det siges i landsbyen Achinathang i Vestladakh: "Vi er en blanding af forskellige slags byg" (Aggarwal 1994). Det er selvfølgelig rigtigt, at muslimer orienterer sig mod den islamiske verden; mange tager på pilgrimsfærd (haj), nogle læser i Qom i Iran eller på Aligarh Muslim University i Indien, og buddhister rejser til Shigatse, Lhasa og andre steder i det centrale Tibet på pilgrimsfart og for deres videre uddannelse. Men disse religiøse orienteringers relevans er situationelt determineret, både socialt og historisk. At være muslim eller buddhist betyder forskellige ting for forskellige individer og er aldrig bare en simpel reproduktion af givne kulturelle værdier eller dogmatisk tro. Den nu afdøde præsident for Ladakhs Muslim Association røg f.eks. cigaretter og drak meget i al offentlighed, og han var ligeglad med, hvad 'gode muslimer' mente om hans adfærd. Han var blevet valgt for sin politiske kompetence ikke for sin religiøse hengivenhed. Derfor kunne han udmærket repræsentere muslimerne.

Det er klart at en taksonomisk eksercits, hvor man klassificerer Ladakhs befolkning efter religiøst tilhørsforhold, og Ladakhs kulturelle og sociale praksis efter kulturelle idealer abstraheret fra et tredje sted, ikke vil hjælpe særlig meget til at forstå, hvordan folk i regionen identificerer sig, eller hvad religiøs identitet betyder i samfundet. Men det er netop denne måde at klassificere verden på, som kulturfundamentalismen og nogle former for multikulturalisme bygger på.

\section{Tredje identiteter?}

“Hybridity is almost a good idea, but not quite.” (Thomas 1996, 9)

En anden måde at forstå Ladakh på ville være at tage udgangspunkt i ideen om det synkretistiske subjekt og om kulturel hybriditet, som den nævnte bosættelsesfortælling lægger op til. I de senere år er der udkommet megen litteratur om multikulturalisme og fremtiden for kulturelle forskelle. Globaliseringen, der ligesom identitet er et vanskeligt begreb klædt i en ‘common sense’ selvfølgelighed, menes af nogle at føre til en gradvis, men uundgåelig udviskning af kulturelle forskelle, mens andre teoretikere insisterer på, at forskellene vil blive fremhævet og føre til kultursammenstød. Ud fra empiriske studier kan man konkludere, at verdens udvikling i de senere år er kendetegnet ved en kombination af delvist modsatrettede processer. På den ene side er der utvivlsomt en proces mod global integration i gang, som også indebærer en spredning af specifikke kulturelle produkter og ideer, skønt fortolkningen og modtagelsen af dem kan være meget forskel- 
lig. Eksempler, som ofte fremhæves, er spredningen af Barbie-dukker, Coca Cola og Lego. Samtidig er der også mange eksempler på, hvad nogle har kaldt lokalisering, og som ofte indebærer en kulturel lukning udadtil. Spørgsmålet er, om ideen om multikulturalisme og hybriditet bryder med denne form for identitetsfetichisme.

Der er som sagt blandt antropologer udbredt enighed om, at kulturer og identiteter skal forstås som dynamiske processer og som synkretistiske. Men at tale om synkretisme eller kulturelle hybrider forudsætter en konceptuel skelnen mellem givne 'rene' kulturer. Problemet med hybriditetsbegrebet er, at det giver indtryk af et voluntaristisk spil, der benægter realiteten af sociale identifikationer, identitetsdiskurser, og vigtigst af alt deres institutionalisering og autorisering (Asad 1993). Det er netop denne strukturerende kontekst, som skal tages med i enhver analyse af, hvorfor, hvordan og hvornår bestemte former for identitet bliver dominante og får den særlige aura af selvfølgelighed, som gør det muligt at tænke dem som 'kulturmøder'.

Meningen er ikke at benægte eksistensen af kulturelle forskelle eller den relationelle dimension af kulturel forandring, som begreber som akkulturation, assimilering, synkretisme og deres nutidige variant hybriditet henviser til. Men der er gode grunde til at udfordre både henvisningen til en oprindelig position af rene og autentiske kulturer, identiteter og religioner og den alternative forestilling om et frit spil af symbolske betegnelser. Udgangspunktet skal være, at alle kulturer, identiteter, religioner per definition altid allerede er af den 'tredje' slags: synkretistiske, hybride, kreoliserede.

Det betyder, at vi skal analysere konkrete repræsentationer af identitet: hvorfor folk identificerer sig selv, andre og deres identiteter på en bestemt måde. Hvis vi ikke problematiserer identifikation og identiteter på denne måde, er vi dømt til den form for tautologi, som Wittgenstein (1995, 350) allerede karakteriserede som nytteløs. Religiøs identitet betyder noget andet i Danmark end i Holland og for forskellige grupper mennesker og for individer i disse lande. At fastslå at det er på grund af kulturforskelle, er tautologisk. Derudover ville vi reducere folk til at være 'opførere' af deres kulturer i stedet for at være aktører. Det betyder, at man skal tage udganspunkt i social praksis. Som Roger Friedland (2001, 141) skriver: "Social practice is both referent and signifier; it is an ontological performance.”

Det er ikke nok at tage udgangspunkt i individuelle aktørers handlinger og overvejelser. Hverken voluntarisme eller rendyrket instrumentalisme, hvor individer og grupper som oftest behandles som kollektive individer, reduceres til små profitmaksimerende entreprenører, evigt på jagt efter symbolsk og materiel kapital. Social praksis begrænses og fremmes af historiske og samtidige forudsætninger, ligesom individer selv er forskelligt situeret. Religiøse identiteters tiltagende betydning skal selvfølgelig ikke reduceres til en effekt af eller en simpel reaktion på (post-)modernitet eller globalisering, men de politiske og institutionelle dimensioner er mindst lige så vigtige at inddrage for at forstå sådanne fænomener som kulturelle normer og værdier.

Selve ideen om kulturmødet skal derfor ikke kun ses som et videnskabeligt problem, der refererer direkte til et objektivt fænomen. Begrebet skal, ligesom den kulturforståelse der ligger bag, forstås som en stillingtagen, som et kulturelt og politisk produkt af historiske processer og projekter. Problemet med forestillinger om hybriditet som noget 
nyt og om kulturmødet som et problem, bygger på en romantisk forestilling om en fortid, hvor man vidste, hvem man selv og andre var, og alle boede trygt inden for deres kulturer og samfund. Og alt var godt. Kulturmøder er ud fra dette synspunkt altid vanskelige og endog unaturlige situationer. Ideen om tredje-identiteter som hybrider eller multikulturalismens lovprisning af kulturel mangfoldighed bygger i grunden på den samme problematiske logik. Antropologisk forskning har givet utallige eksempler på, at disse antagelser er uholdbare.

\section{Konklusion}

Frem for at betragte kulturmøder og den hybriditet, der postuleres at være deres produkt, som nye eller usædvanlige fænomener, skal den bricolage, den kreative interpretation og reinterpretation af selvet og andre, os og dem, den ene og den anden identitet, ses som selve det kulturelle. Det at skabe imaginære ordener i verden, ikke bare en, men flere samtidig med forskellige formål og forskellig relevans til forskellige mennesker og situationer på tværs af tid og rum, er, hvad mennesker (og grupper af mennesker) praktiserer hele tiden. Mennesker er generelt på grund af deres erfaring, kulturelle ressourcer osv. veludrustede til at håndtere det uventede, det ukendte, det nye og de andre. At fremmede har andre skikkelser, er noget, som ikke per definition er overraskende eller truende, men noget som er med til at definere og identificere dem. I hverdagens interaktion med andre mennesker trækker vi i høj grad på vores (kulturelle) stereotyper og forventninger om andre menneskers holdninger og adfærd. Verden er kompleks og livet uforudsigeligt. Det, vi kalder kultur, er med til at gøre det muligt at håndtere denne kompleksitet og uforudsigelighed. Det er bare nødvendigt at huske på, at vores stereotyper og andre kulturelle generaliseringer og vores repræsentationer af os selv og andre ikke er identitisk med 'dem'. Kulturer mødes altså aldrig. Men mennesker gør, og det er hverken noget nyt eller noget problem.

\section{Litteratur}

AggaRWAL, Ravina

1994 From Mixed Strains of Barley Grain: Person and Place in a Ladakhi Village. Ph.D. Dissertation, Department of Anthropology, Indiana University, Bloomington.

ANDERSON, BENEDICT

1991 Imagined Communities: Reflections on the Origin and Spread of Nationalism, London.

1998 "Nationalism, Identity, and the Logic of Seriality", The Spectre of Comparisons: Nationalism, Southeast Asia and the World, London, 29-45.

ASAD, TALAL

1993 Genealogies of Religion: Discipline and Reasons of Power in Christianity and Islam, Baltimore.

BARTH, FREDRIK

1989 “The Analysis of Culture in Complex Societies,” Ethnos 54 (3-4), London, 120-42.

BAYART, JEAN-FRANÇOIS

1997 L'illusion identitaire, Paris.

BEEK, MARTIJN VAN 
2000a "Beyond Identity Fetishism: 'Communal' Conflict in Ladakh and the Limits of Autonomy”, Cultural Anthropology 15 (4), Washington, 525-69.

2000b "Dissimulations: Representing Ladakhi 'Identity'”, Henk Driessen and Ton Otto, eds., Perplexities of Identification: Anthropological Studies in Cultural Differentiation and the Use of Resources, Aarhus, 164-88.

2001 "Public Secrets, Conscious Amnesia, and the Celebration of Autonomy for Ladakh", Thomas Blom Hansen and Finn Stepputat, eds., States of Imagination: Ethnographic Explorations of the Postcolonial State, Durham and London, 365-90.

BНАВНА, НОMI

1994 The Location of Culture, London.

BILLIG, MiCHAEL

1995 Banal Nationalism, London.

CARLSON, JEFFREY.

2000 "Pretending to Be Buddhist and Christian: Thich Nhat Hanh and the Two Truths of Religious Identity”, Buddhist-Christian Studies 20, Honolulu, 115-25.

FRIEDLAND, ROGER

2001 “Religious Nationalism and the Problem of Collective Representation”, Annual Review of Sociology 27, Palo Alto, 125-52.

HANNERZ, ULF

1999 "Reflections on Varieties of Culturespeak", European Journal of Cultural Studies 2 (3), London, 395-407.

HERZFELD, MiCHAEL

1992 The Social Production of Indifference: Exploring the Symbolic Roots of Western Bureaucracy, Chicago.

1996 Cultural Intimacy: Social Poetics in the Nation-state. London.

HunTINGTON, SAMUEL

1993 “The Clash of Civilizations?”, Foreign Affairs 72 (3), New York, 22-49.

1996 The Clash of Civilizations and the Remaking of World Order, New York.

KAKAR, SUDHIR

2000 "The Time of Kali: Violence between Religious Groups in India”, Social Research 67 (3), New York, 877-99.

KREUTZMANN, HERMANN

1998 "From Modernization Theory towards the "Clash of Civilizations': Directions and Paradigm Shifts in Samuel Huntington’s Analysis and Prognosis of Global Development”, GeoJournal 46 (4), Dordrecht, 255-65.

MARX, KARL

1978 “Theses on Feuerbach”, Richard Tucker, ed., The Marx-Engels Reader, New York and London, 143-145.

MufTI, AAMIR R.

2000 “The Aura of Authenticity”, Social Text 18 (3), 87-103.

ORTA, ARTURO

1999 "Syncretic Subjects and Body Politics: Doubleness, Personhood, and Aymara Catechists”, American Ethnologist 26 (4), 864-89.

SPIVAK, GAYATRI CHAKRABORTY

1999 A Critique of Postcolonial Reason: Toward a History of the Vanishing Present, Cambridge, MA.

STOLCKe, VERENA

1995 “Talking Culture: New Boundaries, New Rhetorics of Exclusion in Europe”, Current Anthropology 36 (1), 1-13. 


\section{Martijn van Beek}

SÖKEFELD, MARTIN

1999 "Der Kulturbegriff in der Ethnologie und im öffentlichen Diskurs: eine paradoxe Entwicklung?”, Georg Stöber, ed., 'Fremde Kulturen’ im Geographieunterricht. Analysen, Konzeptionen, Erfahrungen, Hannover, 119-37.

2001 "Reconsidering Identity", Anthropos 96, 527-44.

THOMAS, NicHOLAS

1996 “Cold Fusion”, American Anthropologist 98 (1), Washington, 9-25.

WITTGENSTEIN, LUDWIG

1995 "Philosophische Untersuchungen”, Werkausgabe Band 1. Tractatus logico-philosophicus u.a., Frankfurt a.M.

\section{Summary}

Taking as its starting point Huntington's thesis of a clash of civilisations, this article reviews anthropological critiques of primordialist conceptions of culture and identity as expressed in both cultural fundamentalist and multiculturalist understandings. The example of the Ladakh region of Jammu and Kashmir in India is used to show that multiplicity and syncretism are the very substance of practices of identification, even where clear and at times antagonistic divisions between religious communities are found. The assumption that xenophobia is a necessary or natural reaction to the encounter with others is therefore rejected as an expression of identity fetishism.

Martijn van Beek

Lektor, ph.d.

Afdeling for Etnografi og Socialantropologi

Aarhus Universitet 